\title{
Development and Validation of Stability-Indicating GC-FID Method for the Quantitation of Memantine Hydrochloride and Its Nonchromophoric Impurities in Bulk and Pharmaceutical Dosages
}

\author{
Sanjay A. Jadhav, ${ }^{1}$ Shashikant B. Landge, ${ }^{1}$ Navanath C. Niphade, ${ }^{1}$ \\ Saroj R. Bembalkar, ${ }^{2}$ and Vijayavitthal T. Mathad ${ }^{1}$ \\ ${ }^{1}$ Research and Development, Megafine Pharma (P) Ltd., Nashik 422 202, India \\ ${ }^{2}$ Department of Chemistry, Deogiri College, Aurangabad 431004, India \\ Correspondence should be addressed to Vijayavitthal T. Mathad, drvtmathad@yahoo.co.in \\ Received 5 January 2012; Revised 18 March 2012; Accepted 11 April 2012 \\ Academic Editor: Meehir Palit
}

Copyright (C) 2012 Sanjay A. Jadhav et al. This is an open access article distributed under the Creative Commons Attribution License, which permits unrestricted use, distribution, and reproduction in any medium, provided the original work is properly cited.

A stability-indicating method has been developed and validated for the quantitative determination of memantine hydrochloride and its nonchromophoric impurities in drug substance and drug product using gas chromatography coupled with flame ionization detector (GC-FID). The stability-indicating nature of the method has been proved by establishing peak purity and confirming the mass balance of all samples by subjecting them to stress conditions like hydrolysis, oxidation, photolysis, and thermal degradation studies. The chromatographic separation was performed on a fused silica capillary (HP-5, 30 meter, $0.32 \mathrm{~mm}$ and $0.25 \mu \mathrm{m}$ film thickness) column. The method validation results indicate that the method has acceptable specificity, accuracy, linearity, precision, robustness, and high sensitivity with detection limits and quantitation limits ranging from $0.001 \%$ to $0.01 \%$ and $0.004 \%$ to $0.03 \%$, respectively. The effectiveness of the technique was demonstrated by analysis of different bulk sample of Memantine hydrochloride. The proposed GC-FID method was also found to be specific and selective for the analysis of commercial formulation samples.

\section{Introduction}

Memantine hydrochloride is a 1-amino-3,5-dimethyladamantane derivative developed by Merz co. for the treatment of Alzheimer's disease by decreasing abnormal activity in the brain. This medication was approved by US-FDA during 2007 and marketed under the brand name Namenda. Memantine helps people with dementia to think more clearly and perform daily activities more easily [1-3]. Memantine and its process-related impurities, namely, Imp-A, Imp-B, and Imp-C (Figure 1) are small molecules insensitive to UV due to lack of ultraviolet chromophores, and hence the determination of memantine and its related substances in drug substances and drug product was a critical activity during drug testing. Several analytical methods have been reported for the determination of memantine on highperformance liquid chromatography (HPLC) in combination with mass spectrometry and ultraviolet detection or fluorescence detection usually after derivatization with a suitable chromophores or fluorophore [4-11]. Most of these reported liquid chromatography-mass spectrometry (LC-MS) methods require tedious extraction procedures, which are time-consuming, complex, and expensive $[4,5]$. However, some of HPLC methods are intended for the determination of memantine in biological matrices requiring multiple sample preparation, derivatization and thus are not suitable for routine testing in quality control laboratory [6-9]. The one more drawback of fluorescent derivatization method is that the fluorescence detectors are not as common as UV-visible detector in the analytical laboratory 


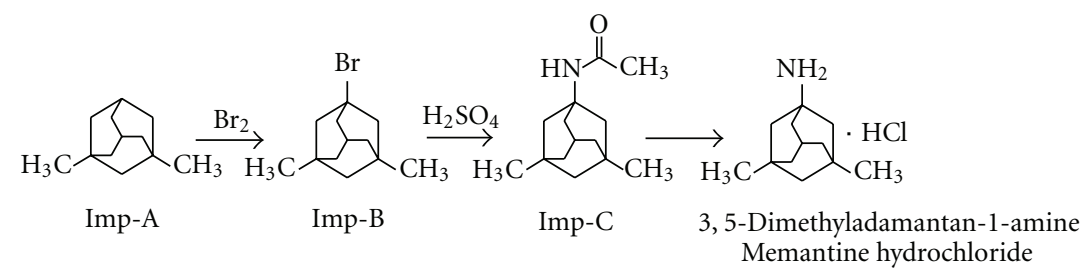

FIgURE 1: Synthetic scheme of memantine hydrochloride.

of a pharmaceutical company. A gas chromatography-mass spectrometry (GC-MS) method has also been reported for determination of memantine in plasma and which is also not convenient for routine analytical testing $[10,11]$. In addition, Michail et al. recently report the photometric methods for determination of memantine by derivatization with NBD$\mathrm{Cl}$ or OPA/NAC reagents in alkaline media [12]. Thus, we felt a need of a simple, suitable, accurate, and stabilityindicating method for the quantification of memantine and its impurities in bulk and formulation samples. Literature survey indicates that there is no stability-indicating GC-FID method available for the determination of memantine and its nonchromophoric impurities, and thus we aimed to develop the same in our analytical laboratory.

Development of "analytical method" for a pharmaceutical product during process research and development in pharmaceutical companies is a critical activity for analytical chemists especially engaged in the generic product due to varied impurities in the API as scheme selected are very specific for their preparation during its life cycle. Understanding of the impurity profile, its structure, and its physical and chemical properties and the study of degradation pathway of API are very important to establish the suitable analytical method. An ideal stability-indicating method is one that quantifies the standard drug alone and also resolves its degradation products. With the advent of International Conference on Harmonization ( $\mathrm{ICH}$ ) guidelines, the requirement of establishment of stability-indicating method has become more clearly mandated [13, 14]. The guidelines explicitly require the conduction of forced decomposition studies under a variety of conditions, like $\mathrm{pH}$, light, oxidation, dry heat, and so forth, and separation of the drug from degradation products. The establishment of purity of chromatographic peak in stressed samples is essential for the validation of the chromatographic method. This is particularly important when developing a stability-indicating method for determination of impurities. Currently various methods are employed for measuring peak purity using a photodiode array detector, which essentially compares the entire UV spectra recorded at various points across the liquid chromatography (LC) peak with the spectrum collected at the apex of the peak. Sometimes this concept is not useful as there are often no spectral data available for the impurity. Gas chromatography (GC) is a very well-established technique for determination of residual solvents, nonchromophoric impurities in drug substance, drug product, and environmental contaminant identification. GC is very rarely used for quantitative determination of impurities in pharmaceutical preparation. Developing a stability-indicating method on GC for impurity profiling in active pharmaceutical ingredients or in pharmaceutical formulation is a challenging task. Complexities involved in development of method are extraction of impurities in presence of salts, selection of suitable diluents for gas chromatographic analysis, and proving stability-indicating nature of the method. The analytes are typically detected using a flame ionization detector (FID) technique. These FID detectors can be used for almost all pharmaceutical products, as they are able to detect any analyte which contains a $\mathrm{C}-\mathrm{C}$ or $\mathrm{C}-\mathrm{H}$ bond. However, in order to analyze compounds using gas chromatography, the compounds must have a high enough vapor pressure to allow them to be volatilized prior to interaction with the chromatographic column. Gas chromatography is a highly efficient, sensitive method used to analyze complex mixtures of substances and nonchromophoric impurities. In our study, a simple stability-indicating GC-FID method was developed and validated for determination of related substance of memantine hydrochloride in drug substances and drug product. The peak purity of stressed samples has been established by comparing mass ion fragmentation pattern with the memantine reference standard using GCMS. All three non-chromophoric impurities (IMP-A, IMP-B, and IMP-C) are well separated from each other. The method was validated as per ICH guideline [15] and successfully applied for separation of all compound of interest in the pharmaceutical formulation. The method reported here may find utility both in the pharmaceutical and chemical industries, and it may potentially be applied to the purity/impurity analysis of other pharmaceutical product analysis.

\section{Experimental}

2.1. Materials and Reagents. The investigated sample of memantine hydrochloride and its potential process-related impurities (Figure 1) were received from synthetic laboratory of Megafine Pharma (P) Ltd, Nashik, India. In addition, analytical reagent grade chloroform and sodium hydroxide were purchased from Merck, (Mumbai, India). Highly pure water obtained from Millipore system (Millipore Inc., USA) was used throughout the analysis.

2.2. GC (Analytical) Instrumentation and Operating Conditions. The GC system used for method development and method validation was Agilent 1200 series (manufactured by Agilent technologies, Waldbronn, Germany) with a liquid 
autosampler. The detection was performed by means of flame ionization detector (FID). The output signal was monitored and processed using Ezchrome Elite software version 3.2.1. The HP-5 ( $30 \mathrm{~m}$ length $\times 0.32 \mathrm{~mm}$ ID, $0.25 \mu \mathrm{m}$ film thickness) column has been procured from Agilent technologies made in USA and used for the method development and method validation studies. The column oven was programmed as follows: initial column oven temperature, $90^{\circ} \mathrm{C}$; hold for $5 \mathrm{~min}$, and increased to $250^{\circ} \mathrm{C}$ at the rate of $10^{\circ} \mathrm{C} / \mathrm{min}$; hold for $10 \mathrm{~min}$. The run time of analysis was $31 \mathrm{~min}$. The injector and detector temperature was kept at $250^{\circ} \mathrm{C}$ and $280^{\circ} \mathrm{C}$, respectively. Nitrogen was used as a carrier gas with a constant pressure of 7.0 psi. The split ratio was set at 20:1 and a $4 \mathrm{~mm}$ i.d., deactivated open-glass tube liner packed with fused silica wool was employed. Sample was injected by the instrument's autosampler with injection volume of $1.0 \mu \mathrm{L}$ and chloroform as the syringe cleaning solvent between injections.

\subsection{Preparation of Standard Solutions and Sample Solutions.} All the samples used for method development and validation were prepared volumetrically. A solution of memantine hydrochloride was prepared at a concentration of $50 \mathrm{mg} / \mathrm{mL}$ and $2 \mathrm{mg} / \mathrm{mL}$ in the chloroform for related substances determination and assay determination, respectively. The individual stock solutions of each impurity at concentration of about $375 \mu \mathrm{g} / \mathrm{mL}$ (impurities Imp-A, B, and C) were prepared in chloroform and diluted further adequately to study the validation attributes. The resultant final diluted solutions were separately transferred into different $125 \mathrm{~mL}$ separating funnel. Extracted as follows, $25 \mathrm{~mL}$ of water and $1.0 \mathrm{~mL}$ aqueous sodium hydroxide solution $(40 \% \mathrm{w} / \mathrm{v})$ were added to each separating funnel, shaked well, and allowed the layers to separate. Collected the lower chloroform layer into another different $125 \mathrm{~mL}$ separating funnel and washed the organic layer by $20 \mathrm{~mL}$ water washing to remove the inorganic salts and allowed the layers to separate. Collected the washed lower chloroform layer in $25 \mathrm{~mL}$ volumetric flask containing about $2.0 \mathrm{gm}$ of anhydrous sodium sulphate, shaked well, and the supernatant liquid was taken for injection. The specification limits used for validation studies were $0.15 \%$ for the known impurities (Imp-A, Imp-B, and Imp-C) and $0.10 \%$ for the any individual unknown impurity. Hence, the system suitability solution of all impurities and memantine was prepared at specification level by diluting above stock solutions.

The test solution was prepared by taking powdered tablets, and a known amount of memantine hydrochloride equivalent to $500 \mathrm{mg}$ was transferred to a $50 \mathrm{~mL}$ volumetric flask along with $10 \mathrm{~mL}$ chloroform and $25 \mathrm{~mL}$ water. The powdered material was dispersed by mixing in an ultrasonic bath for $20 \mathrm{~min}$ and diluted to $50 \mathrm{~mL}$ with diluent. Above solution was centrifuged at $4000 \mathrm{rpm}$ for $15 \mathrm{~min}$ in order to eliminate insoluble excipients and transferred into $125 \mathrm{~mL}$ separating funnel, treated, and extracted as per the above extraction procedure of drug substances. Blank chloroform was prepared by the extraction treatment given to the chloroform.
2.4. Analytical Procedure. $1.0 \mu \mathrm{L}$ of blank chloroform, six replicate injections of system suitability solution, and test sample solution were separately chromatographed. A resolution of not less than 3.0 between any two peaks was set as a system suitability requirement in system suitability solution. To verify the system precision, six replicate injections of system suitability solution were injected and the relative standard deviation (RSD) for Imp-A, Imp-B, Imp-C, and memantine peak areas obtained from six injections were calculated. The RSD of not more than 5.0\% was set as system precision acceptance criteria for Imp-A, Imp-B, Imp-C, and memantine peak areas. All the known related substances Imp-A, Imp-B, and Imp-C in test sample were determined against mean area of respective impurities obtained from replicate injections of system suitability solution. Also, the unknown impurities in test sample were calculated against mean area of memantine obtained from replicate injections of system suitability solution.

2.5. Gas Chromatography-Mass Spectrometry (GC-MS) Analysis. The GC-MS analyses was carried out on Shimadzu GC-MS-QP 2010 gas chromatograph fitted with a HP5 (methylphenylsiloxane, $30 \mathrm{~m} \times 0.32 \mathrm{~mm}$ i.d.) capillary column and was used under the following conditions: carrier gas, nitrogen with a flow rate of $1.0 \mathrm{~mL} / \mathrm{min}$; column temperature, $5 \mathrm{~min}$ hold for $90^{\circ} \mathrm{C}, 90$ to $250^{\circ} \mathrm{C}$ at $10^{\circ} \mathrm{C}$ $\mathrm{min}^{-1}, 10 \mathrm{~min}$ hold at $250^{\circ} \mathrm{C}$; injector temperature, $250^{\circ} \mathrm{C}$; volume injected, $1 \mu \mathrm{L}$ of impurity solution; split ratio, $50: 1$. The MS operating parameters were as follows: ionization potential, $70 \mathrm{eV}$; ion source temperature, $290^{\circ} \mathrm{C}$; quadrupole $100^{\circ} \mathrm{C}$, scan time 3.1 to $31 \mathrm{~min}$, scan speed $2000 \mathrm{amu} / \mathrm{s}$, and scan range 45-450 amu, ion mode $\mathrm{EI}^{+\mathrm{ve}}$.

\subsection{Specificity/Application of Stress (Forced Degradation} Study). Specificity is the ability of the method to measure the analyte response in the presence of its potential impurities. The specificity of the developed GC method for memantine hydrochloride was demonstrated in the presence of its impurities (namely Imp-A, Imp-B, and Imp-C) and degradation products. Forced degradation study was conducted on bulk drug substance in order to prove the stability-indicating property and selectivity of the established method [16]. Forced degradation of memantine was carried out under acid/base hydrolytic, oxidative, thermolytic, and photolytic stress conditions. The drug substances were exposed with concentrated hydrochloric acid (refluxed for $36 \mathrm{~h}$ ), aqueous $5 \mathrm{M}$ sodium hydroxide (refluxed for $36 \mathrm{~h}$ ), and aqueous $30 \%$ hydrogen peroxide (kept for $24 \mathrm{~h}$ at RT). After the degradation, these solutions were extracted with chloroform to a known concentration and analyzed by the proposed method. For thermal stress, sample of drug substance was placed in oven with controlled temperature of $60^{\circ} \mathrm{C}$ for 8 days. For photolytic stress, the sample was exposed to photolytic conditions for 9 days as per ICH guideline. After the exposure to the above stress conditions, solutions of these samples were prepared by dissolving respective samples of known concentration in chloroform and extracted as per extraction procedure and further subjected to analysis 
TABLE 1: System suitability test results.

\begin{tabular}{lccccc}
\hline Compound & Retention time $(\mathrm{min})$ & RRT & Theoretical plate & USP tailing factor $(T)$ & 0.99 \\
Imp-A & 8.04 & 0.74 & 212697 & 1.40 & Resolution $\left(R_{s}\right)$ \\
Memantine & 10.93 & 1.00 & 410875 & 1.04 & 41.92 \\
Imp-B & 13.40 & 1.23 & 728847 & 1.00 & 37.66 \\
Imp-C & 17.36 & 1.59 & 1354612 & 64.75 \\
\hline
\end{tabular}

RRT: relative retention time.

TABLE 2: Forced degradation results.

\begin{tabular}{|c|c|c|c|c|}
\hline Stress condition & $\begin{array}{l}\% \text { Assay of } \\
\text { memantine }\end{array}$ & $\%$ of degradant & Observation and mass balance & Peak purity by GC-MS \\
\hline Undegraded & 98.8 & & - & \\
\hline $\begin{array}{l}\text { Acid hydrolysis } \\
\text { (Conc. } \mathrm{HCl}, 36 \text { h refluxed) }\end{array}$ & 100.6 & Nil & $\begin{array}{l}\text { No any known and unknown } \\
\text { degradation product formed } \\
\text { (Mass balance: } 100.6 \% \text { ) }\end{array}$ & $\begin{array}{l}\text { Mass spectrum similar to the } \\
\text { mass spectrum of reference } \\
\text { standard }\end{array}$ \\
\hline $\begin{array}{l}\text { Base hydrolysis } \\
\text { ( } 5 \mathrm{M} \mathrm{NaOH}, 36 \text { h refluxed) }\end{array}$ & 101.1 & Nil & $\begin{array}{l}\text { No any known and unknown } \\
\text { degradation product formed } \\
\text { (Mass balance: } 101.1 \% \text { ) }\end{array}$ & $\begin{array}{l}\text { Mass spectrum similar to the } \\
\text { mass spectrum of reference } \\
\text { standard }\end{array}$ \\
\hline $\begin{array}{l}\text { Oxidation } \\
\left(30 \% \mathrm{H}_{2} \mathrm{O}_{2}, 24 \mathrm{~h} \text { at RT }\right)\end{array}$ & 76.6 & 24.0 & $\begin{array}{l}24.0 \% \text { of unknown minor } \\
\text { degradation products formed } \\
\text { (Mass balance: } 100.6 \% \text { ) }\end{array}$ & $\begin{array}{l}\text { Mass spectrum similar to the } \\
\text { mass spectrum of reference } \\
\text { standard }\end{array}$ \\
\hline $\begin{array}{l}\text { Thermal } \\
\left(60^{\circ} \mathrm{C}, 8 \text { days }\right)\end{array}$ & 99.2 & Nil & $\begin{array}{l}\text { No any known and unknown } \\
\text { degradation product formed } \\
\text { (Mass balance: } 99.2 \% \text { ) }\end{array}$ & $\begin{array}{l}\text { Mass spectrum similar to the } \\
\text { mass spectrum of reference } \\
\text { standard }\end{array}$ \\
\hline Photolytic as per ICH & 99.2 & Nil & $\begin{array}{l}\text { No any known and unknown } \\
\text { degradation product formed } \\
\text { (Mass balance: } 99.2 \% \text { ) }\end{array}$ & $\begin{array}{l}\text { Mass spectrum similar to the } \\
\text { mass spectrum of reference } \\
\text { standard }\end{array}$ \\
\hline
\end{tabular}

Mass balance $=\%$ assay $+\%$ sum of all impurities $+\%$ sum of all degradants.

using the proposed method. All the stressed samples were quantified for memantine and its impurities. The mass balance ( $\%$ assay $+\%$ of impurities $+\%$ of degradation products) was calculated for all of the samples. GC-MS analysis was employed to check and ensure the homogeneity and purity of memantine peak in all the stressed sample solutions.

2.7. Synthesis of Memantine Hydrochloride. The reaction scheme for the synthesis of memantine hydrochloride is shown in Figure 1 [17]. The chemical name of possible three process related impurities is 1,3-dimethyladamantane (ImpA), 1-bromo-3,5-dimethyladamantane (Imp-B), and $\mathrm{N}$-(3,5dimethyl-1-adamantyl)acetamide (Imp-C), whose area percentage in the crude samples is ranged from 0.05 to $0.2 \%$ consistently.

\section{Results and Discussion}

3.1. Detection of Impurities. Laboratory batches of crude memantine hydrochloride were analyzed for their related substances identification using the developed GC-FID method. These samples were subjected to GC-MS analysis. Imp-B and Imp-C were detected in the crude memantine hydrochloride batch sample. The masses of the detected peaks observed on GC-MS were noted. On the basis of $\mathrm{m} / \mathrm{z}$ value and NIST library search (Shimadzu, Kyoto, Japan), the possible structures for potential impurities suggested are shown in Figure 1. Evaluation of synthetic scheme adopted for memantine hydrochloride and basic raw materials used for the construction of intermediates were considered for understanding the potential process related impurities. These impurities (Imp-A, Imp-B, and Imp-C) were received from R\&D laboratory of Megafine Pharma (P) Ltd and coinjected with memantine hydrochloride to confirm the retention times.

3.2. Development of Chromatographic Conditions. The coreobjective of the present study is to develop a simple, rapid, and stability-indicating GC-FID method capable of eluting and resolving memantine, its process-related and degradation-related impurities within the short run time that complies with the general requirement of system suitability. During the method development, the optimized conditions using the HP-5 column gave excellent separation of the impurities in memantine hydrochloride bulk drug substance but poor peak shape of memantine was noticed. The memantine hydrochloride assay concentration was injected with different chromatographic conditions, but the peak shape was not improved satisfactorily (Figure 2(a)) mainly could be due to hydrochloride salt. The poor peak shape of memantine designated that there was need to optimize the suitable extraction procedure and then need to optimize the chromatographic conditions. 


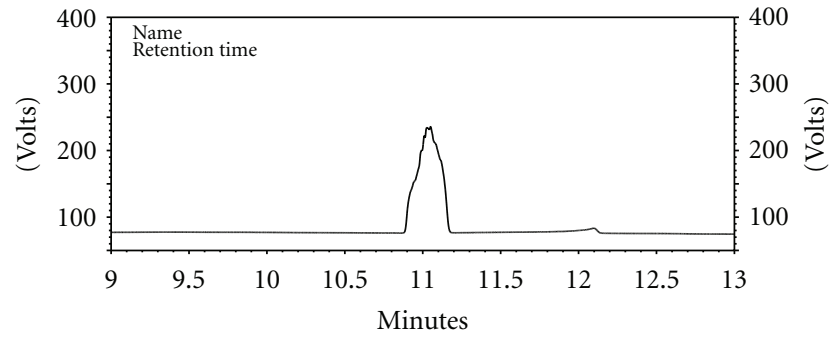

(a)

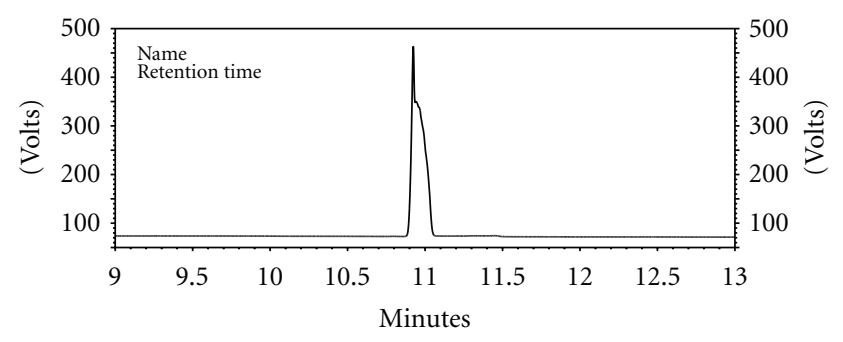

(b)

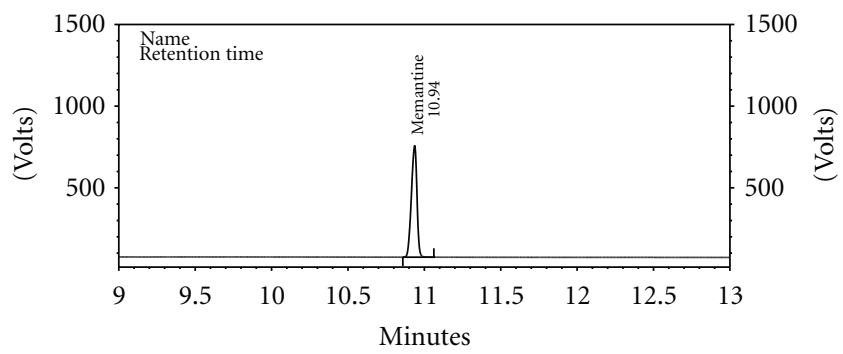

(c)

FIgURe 2: GC-FID method development chromatogram during extraction procedure optimization; (a) test preparation injection before extraction, (b) test preparation injection during optimization of extraction procedure, and (c) test preparation injection after extraction.

3.2.1. Optimization of Extraction Conditions. In order to obtain best extraction efficiency, we used the peak area of memantine standard as the GC response and peak shape to evaluate the extraction efficiency under different conditions. To optimize the method, all extractions were initially carried out on standard stock solution. Suitable organic solvent for GC analysis was identified based on the extractability of memantine hydrochloride from aqueous solution. Solvents such as n-heptane, methylene dichloride, n-hexane, and chloroform were screened for extraction of memantine hydrochloride from aqueous samples. Memantine hydrochloride being highly soluble in chloroform as compared with other solvents experiments with chloroform showed best extraction efficiency of memantine and its three impurities. Efficient extraction in chloroform also played an important role in improving the peak shape of memantine substantially as shown in Figure 2.

3.2.2. Optimization of Chromatographic Conditions. During the method development, different chromatographic parameters were optimized to obtain an acceptable peak shape and resolution between the two peaks with acceptable recoveries to satisfy the GC system suitability. These parameters include flow rate (5-10 psi, at constant pressure), initial column temperature $\left(80-150^{\circ} \mathrm{C}\right)$, and injector temperature $\left( \pm 10^{\circ} \mathrm{C}\right)$. Also various capillary GC columns (HP-5, DB-1701, and SPB-1 with different film thickness) were screened during the method optimization. Among those tested, the SPB-1 $(30 \mathrm{~m}$ length $\times 0.32 \mathrm{~mm} \mathrm{ID,} 1 \mu \mathrm{m}$ film thickness) and DB-1701 ( $30 \mathrm{~m}$ length $\times 0.32 \mathrm{~mm}$ ID, $1 \mu \mathrm{m}$ film thickness) columns gave reasonable retention times at lower temperatures, but these stationary phases shown slightly more bleed and had a baseline shift over the temperature range used. Satisfactory selectivity, sensitivity, resolution, and speed of chromatographic separation with stable baseline were only achieved on HP-5 column ( $30 \mathrm{~m}$ length $\times 0.32 \mathrm{~mm}$ ID, $0.25 \mu \mathrm{m}$ film thickness) with nitrogen as a carrier gas under the chromatographic conditions as described in Section 2.2. The run time of analysis was $31 \mathrm{~min}$. In the optimized conditions, the memantine and all the three nonchromophoric impurities were well separated with a resolution greater than ten. The typical retention times of Imp-A, Memantine, Imp-B, and Imp-C were about $8.1,10.9,13.4$, and $17.3 \mathrm{~min}$, respectively (Figure 3). The developed GC-FID method was found to be specific for determination related substances and assay in drug substance and drug product. For peak identification, a solution containing Imp-A, Imp-B, and Imp-C spiked with authentic samples of memantine hydrochloride at levels of $0.15 \%$ (with respect to target analytical concentration) was injected, and the peak identities were confirmed by GC-MS.

3.3. System Suitability Criteria. A system suitability test was defined based on the results obtained in several representative chromatograms. The column efficiency determined from the analyte peak $>100000$, resolution between two analyte peaks $>10.0$, and RSD for impurity areas in six replicate injection of system suitability solution was $<5.0 \%$. All the system suitability criteria during validation of the study and batch analysis study were within the acceptance limit. The results of system suitability are depicted in Table 1.

\subsection{Validation}

3.4.1. Specificity (Selectivity). The stability-indicating property of analytical method for memantine hydrochloride was established by targeting 10-30\% degradation of memantine. The degradation was not observed in memantine hydrochloride sample when sample exposed to stress conditions like photolytic, thermal, acid, and base hydrolysis. Considerable degradation of memantine hydrochloride was observed under oxidative hydrolysis only. The GC-MS data (mass-ion fragmentation) of memantine indicated that the memantine peak is homogenous and spectrally pure in all the stress conditions tested. The typical chromatogram of memantine test sample after degradation under oxidative conditions is shown in Figure 4 and GC-MS spectra for memantine in unspike test preparation, spiked test preparation and peroxide treated test preparation are shown in Figure 5. The mass balance is a process of adding together the assay value 
TABLE 3: Linearity, limit of detection (LOD), and limit of quantitations (LOQ) data for memantine hydrochloride and related substances.

\begin{tabular}{lcccc}
\hline Component & $\begin{array}{c}\text { Linearity results }(\mathrm{LOQ} \text { to } 250 \% \\
\left.\text { of specification level }{ }^{\mathrm{a}}\right) \\
\text { Regression equation }\end{array}$ & CC $^{\mathrm{b}}(r)$ & LOQ $\mu \mathrm{g} / \mathrm{mL},(\% \text { w.r.t.) })^{\mathrm{c}}$ & \multicolumn{2}{c}{ LOD $\mu \mathrm{g} / \mathrm{mL},(\% \text { w.r.t. })^{\mathrm{c}}$} \\
\hline Imp-A & $y=1236.60 x-346.02$ & 1.00000 & $2.941(0.006)$ & $0.971(0.002)$ \\
Imp-B & $y=817.18 x-5032.36$ & 0.99951 & $5.421(0.011)$ & $1.789(0.004)$ \\
Imp-C & $y=992.21 x-602.22$ & 0.99999 & $3.491(0.007)$ & $1.152(0.002)$ \\
Memantine & $y=921.02 x-2420.30$ & 0.99991 & $5.985(0.012)$ & $1.975(0.004)$ \\
\hline
\end{tabular}

$0.15 \%$ of all related substances and $0.10 \%$ of memantine hydrochloride.

${ }^{\mathrm{b}} \mathrm{CC}$ : correlation coefficient.

${ }^{c}$ LOD LOQ values are in $\%$ with respect to test concentration of $50 \mathrm{mg} / \mathrm{mL}$.

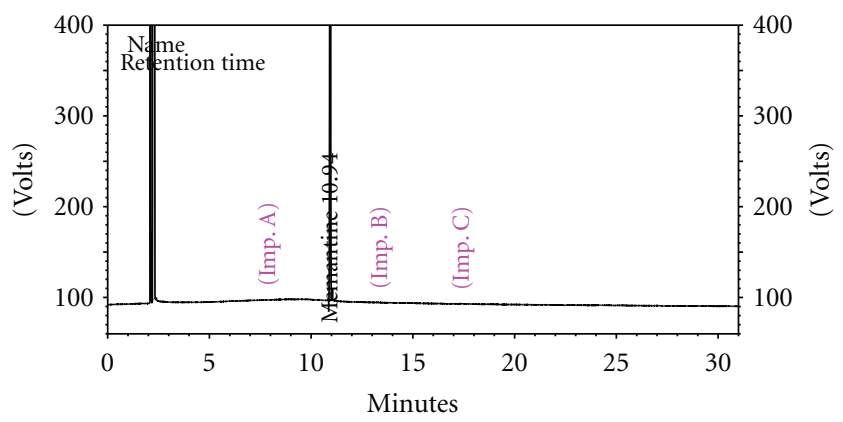

(a)

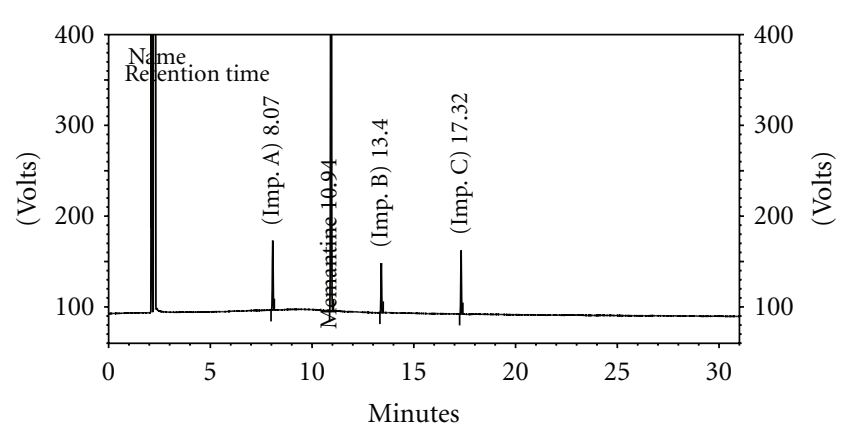

(b)

Figure 3: Typical GC-FID chromatograms of (a) memantine hydrochloride unspiked test preparation, (b) memantine hydrochloride spiked test preparation with known impurities (Imp-A, Imp- $\mathrm{B}$, and Imp-C).

and the levels of degradation products to see how closely these add up to $100 \%$ of initial value with due consideration of the margin of analytical error [18].

The resultant mass balance of stressed samples was about $99.0 \%$. The data on forced degradation studies are summarized in Table 2. The results on degradation studies revealed that the degradation products were well separated from the memantine. No peaks coeluted with the memantine

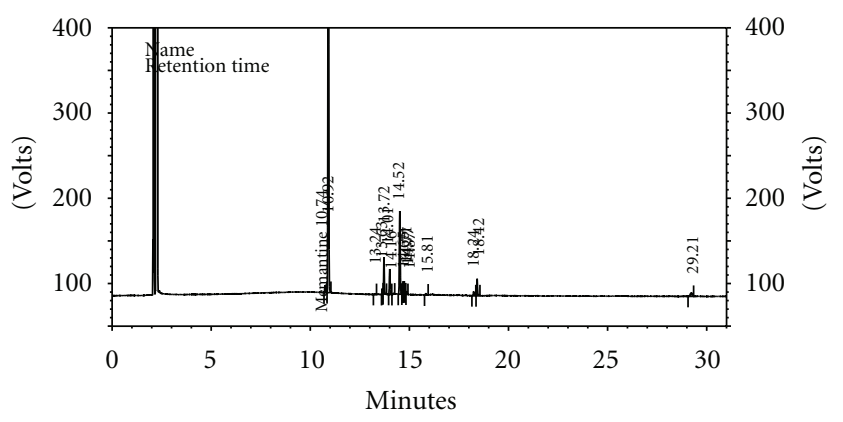

Figure 4: Typical GC-FID-forced degradation chromatogram of peroxide treated test preparation.

peak, suggesting the method enabled specific analysis of memantine in the presence of its degradation products.

3.4.2. Linearity. The linearity of method was established at two different levels. The assay linearity was studied by preparing five different solid weighings of memantine hydrochloride from 50 to $150 \%$ w/w $(50,75,100,125$, and $150 \% \mathrm{w} / \mathrm{w}$ ) with respect to target analytical concentration $(2000 \mu \mathrm{g} / \mathrm{mL})$ and injected. Linearity test solutions for related substance were prepared by diluting the impurity stock solution (as described in the Section 2.3) to the required concentrations. The solutions were prepared at six concentration levels from LOQ to 250\% (LOQ, 50, 100, 150,200 , and $250 \%$ ) with respect to the specification level of impurities. The data were subjected to statistical analysis using a linear-regression model; the regression equations and correlation coefficients are given in Table 3 . The results showed an excellent correlation between the peak areas and concentrations of Imp-A, Imp-B, Imp-C, and memantine.

3.4.3. Limits of Detection and Quantitation (LOD and LOQ). According to ICH Q2R1 recommendations, the limits of detection (LOD) and quantitation (LOQ) for memantine and its key impurities (Imp-A, Imp-B, and Imp-C) were estimated by calibration curve method (residual standard deviation $(\sigma)$ and the slope (S) of regression line), by injecting series of dilute solutions of known concentration. 
Rt-9.04 (base peak $m / z$ 108)

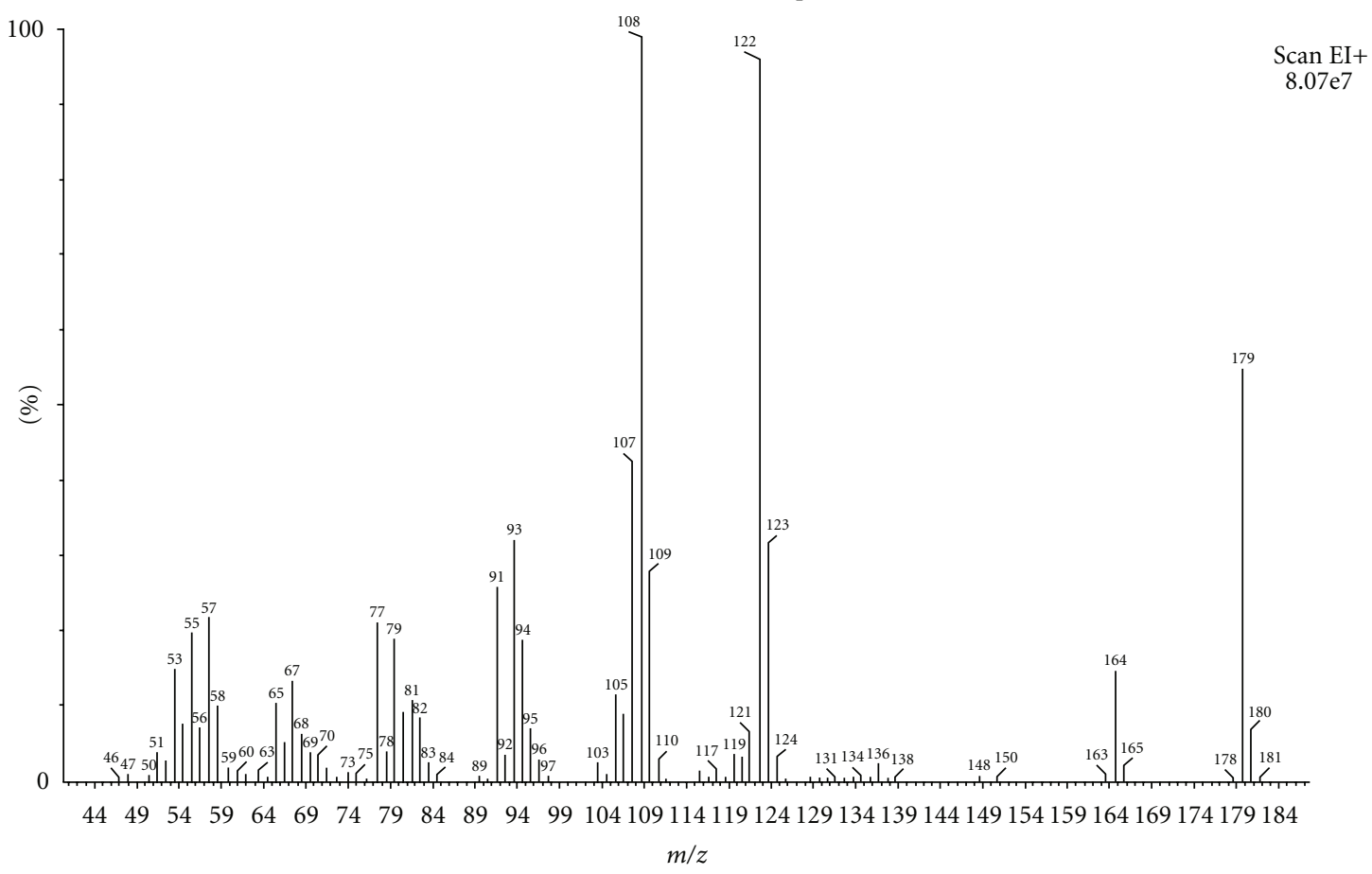

(a)

Rt-9.04 (base peak $m / z$ 108)

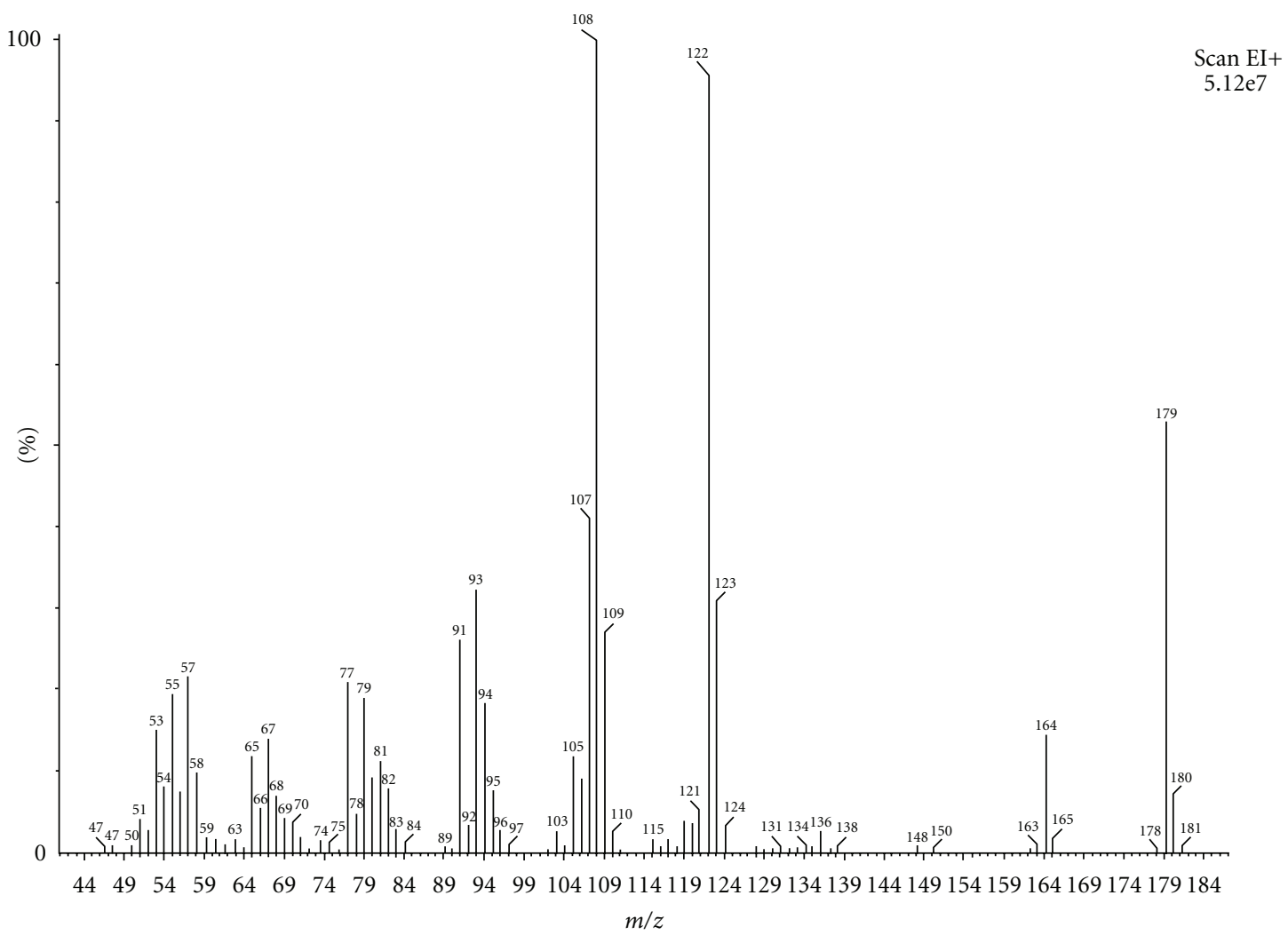

(b)

FIgURe 5: Continued. 
Rt-9.05 (base peak $m / z$ 108)

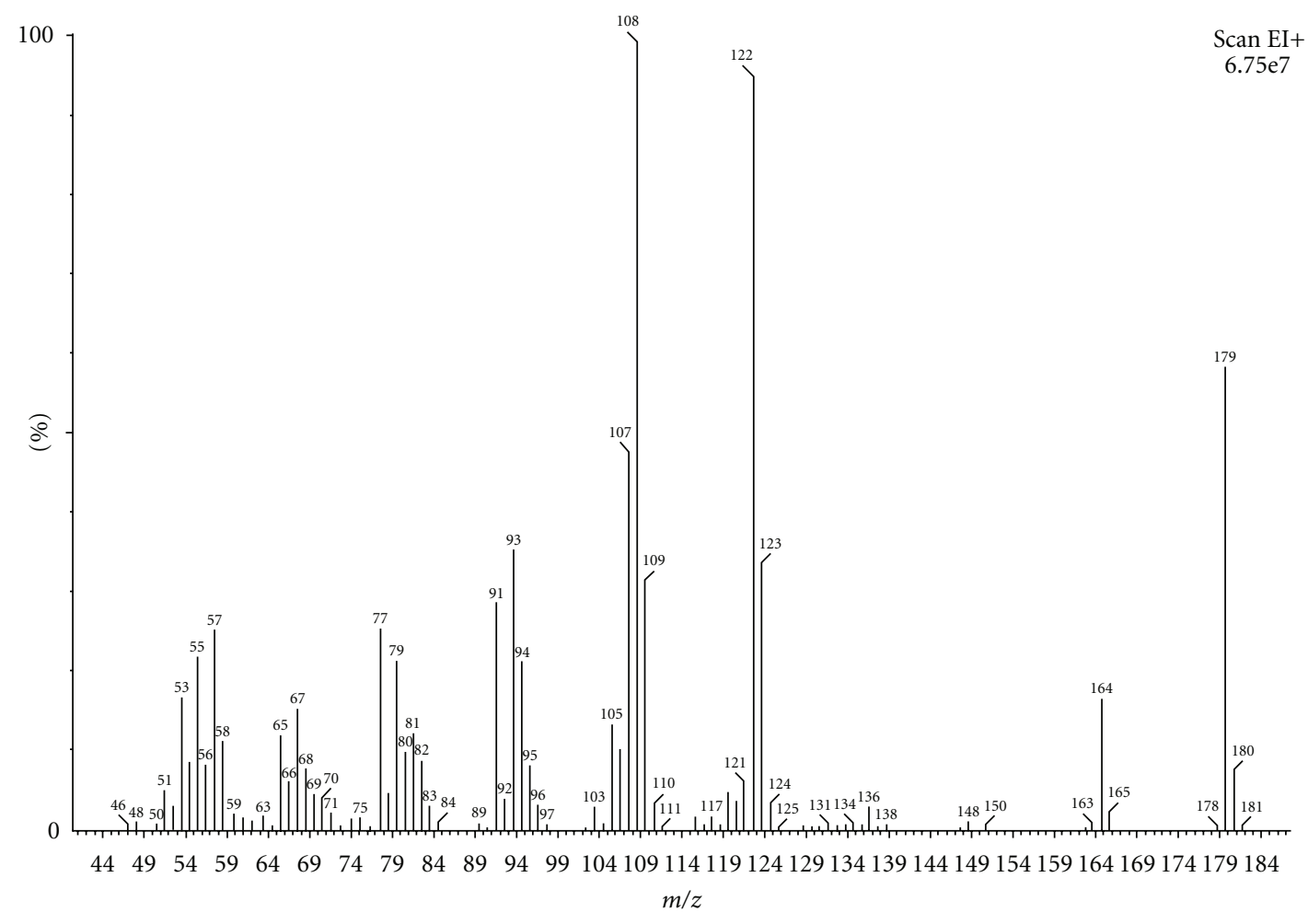

(c)

Figure 5: Typical GC-MS spectra of memantine in (a) unspiked test preparation, (b) spiked test preparation, and (c) peroxide treated test preparation.

TABLE 4: Validation data results of related substances and assay of memantine hydrochloride.

\begin{tabular}{lcccc}
\hline Compound & \multicolumn{2}{c}{ Related substances results } & Imp-B & $\begin{array}{c}\text { Assay results } \\
\text { Imp-C }\end{array}$ \\
\hline & \multicolumn{1}{c}{ Precision } & (mean results \pm RSD) & & \\
Method precision $(n=6)$ & $0.155 \pm 1.29$ & $0.167 \pm 1.20$ & $0.153 \pm 1.31$ & $99.9 \pm 0.44$ \\
Intermediate precision $(n=6)$ & $0.165 \pm 1.21$ & $0.165 \pm 1.82$ & $0.168 \pm 1.19$ & $100.4 \pm 0.73$ \\
Overall results $(n=12)$ & $0.160 \pm 3.13$ & $0.166 \pm 1.81$ & $0.161 \pm 4.97$ & $100.1 \pm 0.62$ \\
\hline
\end{tabular}

The LOQ and LOD of memantine hydrochloride were $5.985 \mu \mathrm{g} / \mathrm{mL}$ and $1.975 \mu \mathrm{g} / \mathrm{mL}$, respectively, whereas the LOD and LOQ for the related substances were in the range of $0.971-1.789 \mu \mathrm{g} / \mathrm{mL}$ and $2.941-3.491 \mu \mathrm{g} / \mathrm{mL}$, respectively. The calculated LOQ concentrations of all the components were further verified for precision by injecting six individual preparations of Imp-A, Imp-B, Imp-C, and memantine hydrochloride. The RSD of LOQ precision was in the range of $0.83-7.19 \%$. These limits of quantification levels of the impurities were helpful for the process research work to control the impurities at the accepted level during the optimization of the process. The results are depicted in Table 3.

3.4.4. Precision. System precision for assay method was verified by injecting the six replicate injections of standard concentration $(5 \mathrm{mg} / \mathrm{mL})$, and RSD of memantine peak area was evaluated and found to be $0.72 \%$. System precision for related substances determination was verified by system suitability solution, which was analyzed for six times and RSD of memantine and all impurities peak areas were evaluated and found to be $0.58 \%$.

Precision of the method was studied for method precision and intermediate precision. The assay method precision was examined by analysing six determinations of the sample solution at working concentration versus a standard concentration, and RSD of obtained results was evaluated and found to be $0.44 \%$. Related substances method precision was demonstrated by analyzing six separate memantine hydrochloride sample solutions that were prepared by spiking the related substances, namely, Imp-A, Imp-B, and Imp-C at specification level. The RSD (1.20$1.31 \%, n=6$ ) for each related substance was evaluated. 
TABle 5: Accuracy data of related substances.

\begin{tabular}{|c|c|c|c|c|}
\hline \multirow{2}{*}{ Component } & \multicolumn{4}{|c|}{ Recovery results (mean $\%$ recovery $(\% \mathrm{RSD}))^{\mathrm{a}}$} \\
\hline & LOQ level; amount (\% w/w) & $\begin{array}{c}50 \% \text { of specification } \\
\text { level }^{\mathrm{b}} ; \text { amount }(\% \mathrm{w} / \mathrm{w})\end{array}$ & $\begin{array}{c}100 \% \text { of specification } \\
\text { level }^{\mathrm{b}} ; \text { amount }(\% \mathrm{w} / \mathrm{w})\end{array}$ & $\begin{array}{c}150 \% \text { of specification } \\
\text { level }^{\mathrm{b}} ; \text { amount }(\% \mathrm{w} / \mathrm{w})\end{array}$ \\
\hline Imp-A & $116.67(0.00)$ & $106.67(3.00)$ & $104.00(2.00)$ & $104.15(3.00)$ \\
\hline Imp-B & $116.67(0.00)$ & $114.86(3.00)$ & $111.94(2.00)$ & $113.36(3.00)$ \\
\hline Imp-C & $112.50(0.00)$ & $102.67(3.00)$ & $100.22(2.00)$ & $100.30(3.00)$ \\
\hline
\end{tabular}

average \% recovery and \% RSD of results of three determinations.

${ }^{b} 0.15 \%$ of all related substances.

TABLE 6: Results (in \%) of formulation tablet and bulk drug batches sample analysis.

\begin{tabular}{|c|c|c|c|c|c|}
\hline \multirow{2}{*}{ Sample source } & \multicolumn{4}{|c|}{ Related substances results } & \multirow{2}{*}{ Assay results } \\
\hline & Imp-A & Imp-B & Imp-C & SUMI & \\
\hline \multicolumn{6}{|c|}{ Formulation product analysis results } \\
\hline Formulation-1 & ND & ND & ND & ND & 99.4 \\
\hline Formulation-2 & ND & ND & ND & ND & 99.9 \\
\hline \multicolumn{6}{|l|}{ Batch analysis results (\%) } \\
\hline B.NO. MEM/A163/IV/08 & ND & ND & ND & 0.01 & 99.7 \\
\hline B.NO. MEM/A163/IV/09 & ND & ND & ND & 0.01 & 99.2 \\
\hline B.NO. MEM/A163/IV/10 & ND & ND & ND & 0.01 & 99.3 \\
\hline
\end{tabular}

ND: not detected

SMUI: single maximum unknown impurity.

In the intermediate precision study, the similar procedure of method precision was carried out by a different analyst, diluent preparations, and instrument on a different day with different lot of same brand column. The percentage relative standard deviation of the results for assay method and related substances method was evaluated and found to be $0.73 \%$ and $1.19-1.82 \%$, respectively. The percentage overall RSD for results of intermediate precision and results of method precision was calculated. The overall $\operatorname{RSD}(n=12)$ of assay and related substances results was found within $0.62 \%$ and $4.97 \%$, respectively. The results were reported in Table 4.

3.4.5. Accuracy (Recovery). Accuracy of the method for all the related substances was determined by analyzing memantine hydrochloride sample solutions spiked with all the related substances at four different concentration levels namely, LOQ, 50, 100, and 150\% of specification level. Each level has been analyzed in triplicate. Table 5 provides validation data results of related substances of memantine hydrochloride. The recovery of all these related substances was found to be in between the predefined acceptance criteria of $80.0-120.0 \%$ [19].

3.4.6. Robustness. To assess robustness of the method, the experimental conditions were deliberately altered and system suitability parameter was evaluated. Nitrogen was used as a carrier gas with a constant pressure of 7.0 psi. To study the effect of flow rate on the resolution, the same was altered by 0.7 units that is from 6.3 to $7.7 \mathrm{psi}$. The effect of column temperature was studied at 93 and $87^{\circ} \mathrm{C}$ instead of $90^{\circ} \mathrm{C}$. The effect of changing the injector temperature by $\pm 10^{\circ} \mathrm{C}\left(240^{\circ} \mathrm{C}\right.$ and $260^{\circ} \mathrm{C}$ instead of $250^{\circ} \mathrm{C}$ ) on resolution was also studied.
All the other chromatographic conditions were held constant as described above.

In all the deliberate varied chromatographic conditions (flow rate, column temperature, and injector temperature), the all system suitability criteria were within the limits (theoretical plate $>100000$, resolution between two analyte peak $>10.0$, and RSD $<5.0 \%$ ), illustrating the robustness of the method.

3.4.7. Stability of Analytical Solution. Sample solutions of memantine hydrochloride spiked with related substances at specified level were prepared and analyzed immediately at different time intervals up to $48 \mathrm{hrs}$ to determine the stability of sample solution. The cumulative \% RSD of memantine and all impurities peak areas was evaluated at each time interval and found to be less than $5.0 \%$. The results from these studies indicated that the sample solution was stable for $48 \mathrm{hrs}$ at room temperature.

3.5. Application of the Method. The analysis of commercial formulation sample and bulk drug sample indicated that the method is specific and selective for determination of related substances in the formulation and bulk drug samples (Table 6). The developed method is capable for quantitative analysis of memantine hydrochloride in the bulk drug and in a pharmaceutical dosage form. The values of impurities detected indicate that the method is capable of detecting known and unknown impurities in routine analysis of bulk drug and formulation sample. 


\section{Conclusion}

This is the first method reported in the literature for the separation and quantitation of memantine and its impurities/degradants. The GC-FID method is specific, linear, sensitive, accurate, precise, and robust. This approach may potentially be applied to the purity/impurity analysis of other acid chlorides or acid halides. The degradation pathway of memantine hydrochloride is established as per ICH recommendations. The stability-indicating GC-FID method developed and used for stress studies is also fit for quantitative, related substance, and assay determination of memantine hydrochloride. The method is validated as per ICH requirements. The developed method is stability indicating which can be used for the impurity testing and assay determination in routine analysis of production samples and also to analyze stability samples.

\section{Acknowledgments}

The authors wish to thank the management of Megafine group for supporting this work. They would also like to thank colleagues in the Division of Research and Development of Megafine Pharma (P) Ltd for their cooperation in carrying out this work.

\section{References}

[1] C. G. Parsons, A. Stöffler, and W. Danysz, "Memantine: a NMDA receptor antagonist that improves memory by restoration of homeostasis in the glutamatergic system-too little activation is bad, too much is even worse," Neuropharmacology, vol. 53, no. 6, pp. 699-723, 2007.

[2] J. W. Johnson and S. E. Kotermanski, "Mechanism of action of memantine," Current Opinion in Pharmacology, vol. 6, no. 1, pp. 61-67, 2006.

[3] J. Sawynok and A. Reid, "Modulation of formalin-induced behaviors and edema by local and systemic administration of dextromethorphan, memantine and ketamine," European Journal of Pharmacology, vol. 450, no. 2, pp. 153-162, 2002.

[4] M. J. Koeberle, P. M. Hughes, C. G. Wilson, and G. G. Skellern, "Development of a liquid chromatography-mass spectrometric method for measuring the binding of memantine to different melanins," Journal of Chromatography B, vol. 787, no. 2, pp. 313-322, 2003.

[5] A. A. Almeida, D. R. Campos, G. Bernasconi et al., "Determination of memantine in human plasma by liquid chromatography-electrospray tandem mass spectrometry: application to a bioequivalence study," Journal of Chromatography B, vol. 848, no. 2, pp. 311-316, 2007.

[6] R. F. Suckow, M. F. Zhang, E. D. Collins, M. W. Fischman, and T. B. Cooper, "Sensitive and selective liquid chromatographic assay of memantine in plasma with fluorescence detection after pre-column derivatization," Journal of Chromatography $B$, vol. 729, no. 1-2, pp. 217-224, 1999.

[7] M. F. Xie, W. Zhou, X. Y. Tong et al., "High-performance liquid chromatographic determination of memantine hydrochloride in rat plasma using sensitive fluorometric derivatization," Journal of Separation Science, vol. 34, no. 3, pp. 241-246, 2011.

[8] A. Zarghi, A. Shafaati, S. M. Foroutan, A. Khoddam, and B. Madadian, "Sensitive and rapid HPLC method for determination of memantine in human plasma using OPA derivatization and fluorescence detection: application to pharmacokinetic studies," Scientia Pharmaceutica, vol. 78, no. 4, pp. 847-856, 2010.

[9] B. Narola, A. S. Singh, P. R. Santhakumar, and T. G. Chandrashekhar, "A Validated stability-indicating reverse phase hplc assay method for the determination of memantine hydrochloride drug substance with UV-detection using precolumn derivatization technique," Analytical Chemistry Insights, vol. 2010, no. 5, pp. 37-45, 2010.

[10] H. J. Leis, G. Fauler, and W. Windischhofer, "Quantitative analysis of memantine in human plasma by gas chromatography/negative ion chemical ionization/mass spectrometry," Journal of Mass Spectrometry, vol. 37, no. 5, pp. 477-480, 2002.

[11] J. Kornhuber, E. M. Kennepohl, S. Bleich et al., "Memantine pharmacotherapy: a naturalistic study using a population pharmacokinetic approach," Clinical Pharmacokinetics, vol. 46, no. 7, pp. 599-612, 2007.

[12] K. Michail, H. Daabees, Y. Beltagy, M. Abdel-Khalek, and M. Khamis, "Spectrophotometric and spectrofluorimetric determination of memantine hydrochloride in bulk and pharmaceutical preparations," International Journal of Pharmacy and Pharmaceutical Sciences, vol. 3, no. 3, pp. 180-185, 2011.

[13] "Guidance for Industry, 3QA Impurities in New Drug Substances," U.S. Food and drug Administration, Rockville, Md, USA, ICH Revision 2, 2008.

[14] "Guidance for Industry, 3QB (R2) Impurities in New Drug Products," U.S. Food and Drug Administration, Rockville, Md, USA, ICH Revision 2, 2006.

[15] International Federation of Pharmaceutical Manufactures \& Associations (IFPMA), Validation of Analytical Procedure, International conference on Harmonization, Q2 (R1), Geneva, Switzerland, 1996.

[16] J. Ruan, P. Tattersall, R. Lozano, and P. Shah, "The role of forced degradation studies in stability indicating HPLC method development," American Pharmaceutical Review, vol. 9, no. 1, pp. 46-53, 2006.

[17] J. Mills and E. Krumkalns, "Adamantyl secondary amines," US patent 3391142, 1968.

[18] M. Bakshi and S. Singh, "Development of validated stabilityindicating assay methods - critical review," Journal of Pharmaceutical and Biomedical Analysis, vol. 28, no. 6, pp. 1011-1040, 2002.

[19] J. Elmer and J. H. M. Miller, Method Validation in Pharmaceutical Analysis - A Guide to Best Practice, Wiley-VCH, Verlag GmbH \& Co. KGaA, Weinheim, Germany, 2005. 


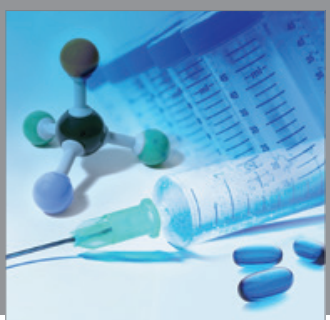

International Journal of

Medicinal Chemistry

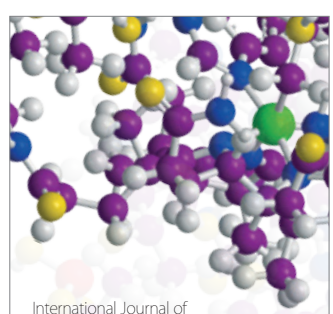

Carbohydrate Chemistry

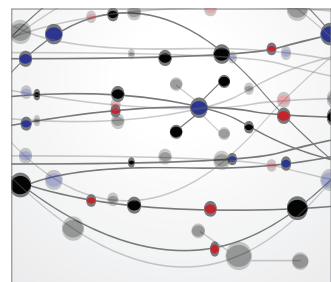

The Scientific World Journal
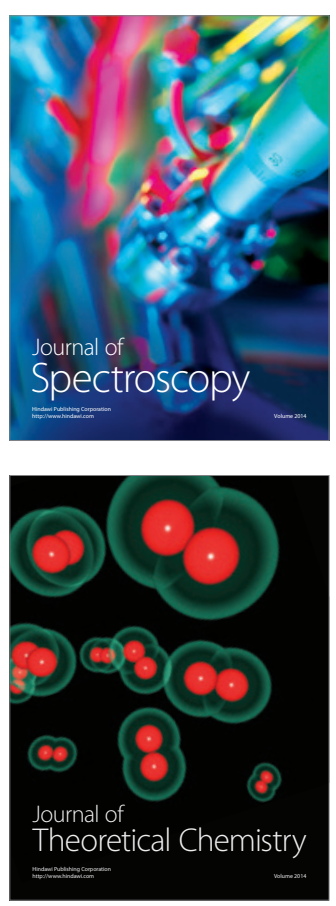
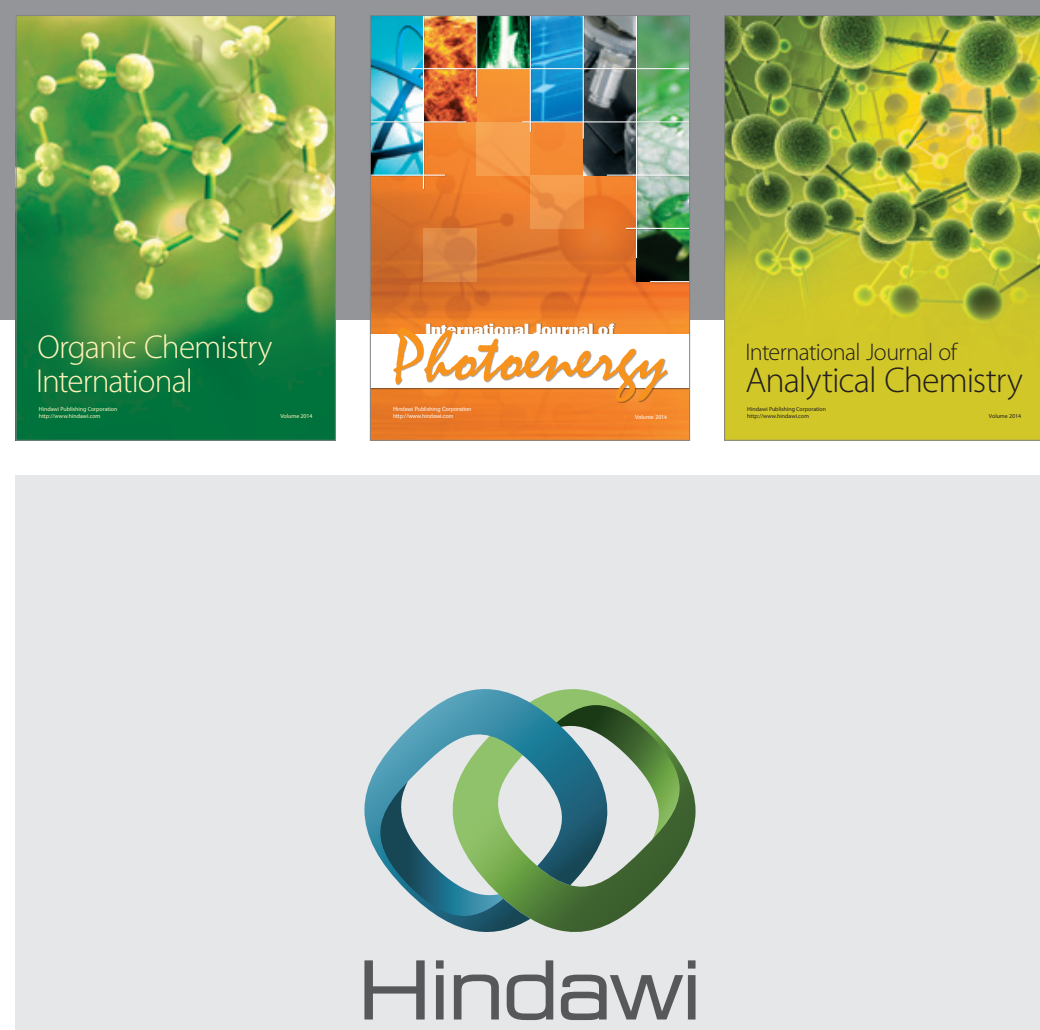

Submit your manuscripts at

http://www.hindawi.com
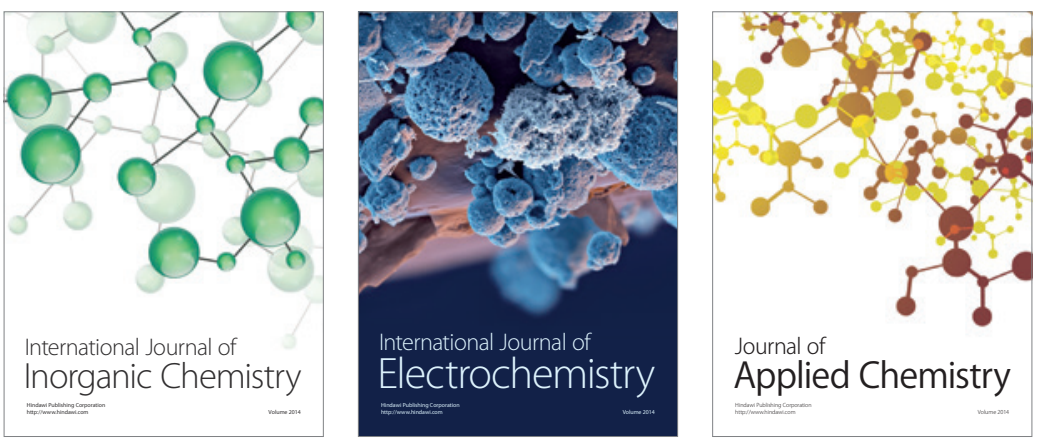

Journal of

Applied Chemistry
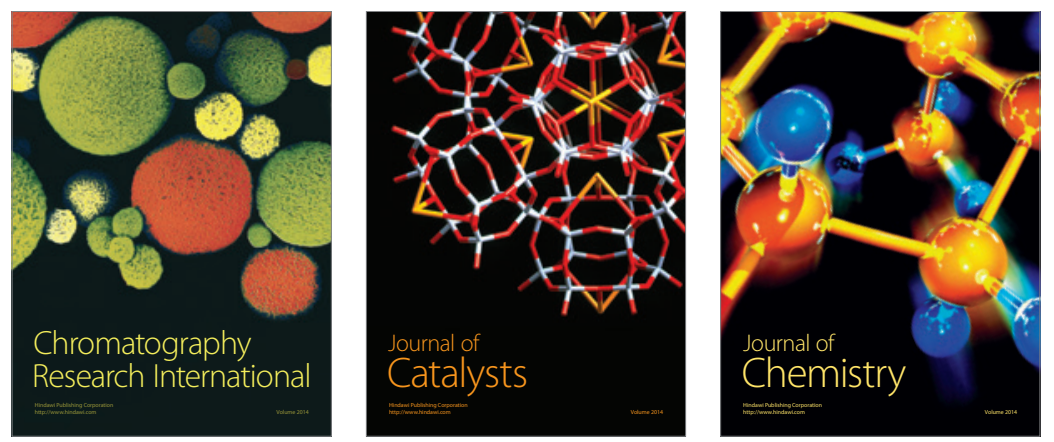
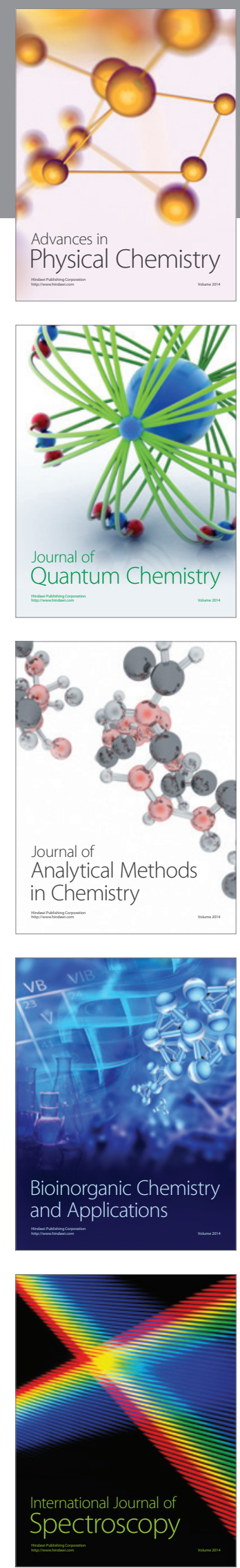